\title{
How important is the coast? A survey of coastal objectives in an Australian regional city
}

Leo X.C. Dutra ${ }^{*}{ }^{1,2}$, Catherine M. Dichmont ${ }^{1}$, Ingrid van Putten ${ }^{3}$, Olivier Thébaud ${ }^{1,4}$, Roy A. Deng ${ }^{1}$, Ricardo Pascual ${ }^{1}$, Randall Owens ${ }^{5}$, Eddie Jebreen ${ }^{6}$, Carolyn Thompson ${ }^{7}$, Warne, M.St.J. ${ }^{8, \#}$, Quinn, R. ${ }^{6}$, Bennett, J. ${ }^{9}$, Read, M. ${ }^{5}$, Wachenfeld, D. ${ }^{5}$, Collier, Catherine ${ }^{10}$, Waycott, Michelle ${ }^{11}$, Davies, J. ${ }^{6}$, Garland, A. ${ }^{6}$, Dunning, M. ${ }^{6}$, Playford, J. ${ }^{8}$

${ }^{*}$ Corresponding author

${ }^{1}$ CSIRO Oceans and Atmosphere, Queensland Biosciences Precinct, 306 Carmody Road, St Lucia, QLD, 4067, Australia.

${ }^{2}$ The University of the South Pacific, Faculty of Science, Technology and Environment, School of Marine Sciences, Laucala Campus, Suva, Fiji.

${ }^{3}$ CSIRO Oceans and Atmosphere, GPO Box 1538, Hobart, TAS, 7001, Australia.

${ }^{4}$ IFREMER, Centre Bretagne, ZI de la Pointe du Diable, CS 10070, 29280 Plouzané, France.

${ }^{5}$ Great Barrier Reef Marine Park Authority, 2-68 Flinders Street, PO Box 1379, Townsville, QLD, 4810, Australia

${ }^{6}$ Queensland Department of Agriculture, Fisheries and Forestry, Primary Industries Building, 80 Ann St, Brisbane, QLD, 4001, Australia.

${ }^{7}$ Great Barrier Reef Marine Park Authority, 43 River Street, Mackay, QLD 4740, Australia

${ }^{8}$ Queensland Department of Science, Information Technology and Innovation, Ecosciences Precinct, 41 Boggo Road, Dutton Park, QLD, 4102, Australia.

${ }^{9}$ Queensland Department of Environment and Heritage Protection, 400 George Street, Brisbane QLD 4000, Australia

${ }^{10}$ Tropical Water and Aquatic Ecosystems Research (TropWATER), James Cook University, 14-88 Smithfield Dve, Cairns, QLD 4870, Australia.

${ }^{11}$ Ecology and Evolutionary Biology, University of Adelaide, Adelaide, SA, 5005, Australia.

\# Current address: Centre for Agroecology, Water and Resilience, Coventry University, Coventry CV1 5FB, United Kingdom. 


\section{$1 \quad 1 \quad$ Introduction}

2 Clearly defining and prioritizing management goals and objectives is a critical part of what

3 constitutes adaptive natural resource management (NRM). Clear goals and objectives help managers

4 and stakeholders evaluate the effectiveness of management interventions by comparing outcomes

5 of these interventions with management objectives, which also helps identify data and information

6 gaps (Thom, 2000; Walters, 2007). Defining and prioritizing management goals and objectives is

7 difficult as it may involve intense stakeholder negotiations (Boschetti, 2007) to make the trade-offs

8 required to manage natural resources (Mackenzie et al., 2006; Rittel and Webber, 1973). To

9 complicate matters, goals and objectives are sometimes implicit rather than explicit in management

10 procedures, or they are not well articulated (Burt, 2011; de Geus, 1988). As a result, conflicts

11 between stakeholders can (and often do) occur in NRM (Walters, 2007; Ward and Schriefer, 1997).

12 Conflicts and challenging negotiation processes happen because individuals and groups rate environmental, social, economic and cultural objectives differently based on their world-views, values and assumptions about the current state of the resource and their expectations for its future state (Boschetti et al., 2012; Pascoe et al., 2013). As a result, the process of defining and prioritising management objectives to support decision-making and policy implementation is strongly influenced by powerful groups and leaders, especially in multiple-use areas, such as the coastal zone 18 (Dutra et al., 2014).

The articulation and prioritization of management objectives for NRM is essential to develop a broad vision about how natural resources are to be used and managed. Targets, which can be explicit or implicit in management plans, give a clear purpose for decisions, also providing accountability and defensibility for the decisions made (Pressey et al., 2003). Goals and objectives' targets are necessary to evaluate progress and effectiveness of management actions/strategies. A process to clearly define and prioritise management objectives strongly supports NRM because it facilitates the negotiation process between managers and stakeholders. Such process helps stakeholders appreciate the trade-offs involved with decisions (Pressey and Bottrill, 2009; Pressey et al., 2003).

This paper describes the outcomes of a collaborative project between researchers, a community group and coastal managers from Mackay (Queensland, Australia) to elicit and prioritise management objectives related to inshore fisheries and biodiversity in the coastal zone of the Great Barrier Reef (GBR). The aims of the research were to: (i) apply and test a collaborative method to elicit management objectives from a community group, (ii) understand the relative importance of management objectives to different stakeholders, and (iii) understand how diverse perceptions about the importance of management goals and objectives can be used to support multiple-use management in Australia's iconic GBR. This is important because Australia attempts to manage coastal resources (e.g. fisheries) using ecologically sustainable development (ESD) principles, which require integrated objectives (social, economic and ecological) to support decision-making (Triantafillos et al., 2014).

The lack of data on what communities want for their future (goals and objectives) can challenge the effective implementation of ESD in coastal Australia because policies that do not consider local needs and aspirations can be ineffective without public support and participation. As a result the research team submitted the results of the project to management agencies, such as the Great 
Innovation, Queensland Department of Environment and Heritage Protection, and Queensland Department of Agriculture, Fisheries and Forestry. As such, this research is expected to contribute to ESD by providing a methodology that helps elucidate what local communities value and propose how this information can be used to support coastal management decisions following ESD principles.

\subsection{Study site}

The extent of the Mackay coastal zone is Midge Point in the north to Broadsound in the south, and the tidal region to 12 nautical miles offshore (Figure 1). Mackay has a population of approximately 75,000 people (Australian Bureau of Statistics, 2012) with a large "Fly in and Fly out" (an employment arrangement characterised by temporarily flying in and out employees to/from the workplace) community associated with the mining industry. Coal mining and agriculture (sugar cane) are the largest economic sectors in the Mackay region (Australian Bureau of Statistics, 2012). Mackay has two active ports (Figure 1): the Port of Mackay, which handles sugar and sugar products, grain and petroleum; and the Port of Hay Point, which is one of the largest coal terminals in the world with two coal export terminals (Dalrymple Bay Coal Terminal, and Hay Point Coal Terminal) (NQBP, 2014).

Recreational fishing is important to Mackay residents. With approximately 19,200 recreational boats registered it has one of the highest ratios of boats per resident in Australia, featuring one boat registered for every four residents (Department of Transport and Main Roads, 2015). Fishers in the Mackay region mostly fish where they live because they have access to excellent marine fishing environments, which is reflected in their catches (e.g. coral trout, yellowfin bream, mud crab, pike bream, cod, and barramundi) (Dichmont et al., 2014).

Commercial fishing is also important in the Mackay region, where the largest constituent of active commercial fishing licences utilise pot and net apparatus in combination to fish for crab and inshore fin fish species (Dichmont et al., 2014). There are extensive commercial fisheries closures in the region imposed by GBR and Queensland marine parks zoning (Marine National Park and Conservation Park zones) and Dugong Protection Areas declared under the Fisheries Act 1994. Trawling is further restricted to General Use zones in the region while recreational fishers are only restricted by Marine National Park zones. The inshore waters of the Mackay region support both beam and otter trawling. In 2010, 42 otter trawlers caught 252.7 tonnes of fish. In 2011 and 2012, 112.2 and 133.9 tonnes of fin fish were recorded through logbook returns; the downturn in catch was directly proportional to the decrease in active commercial licences during the same period. An increase to 247.4 tonnes was recorded in 2013.

Among the key habitats in the region are coral reefs, mangroves and seagrass. There are also important populations of threatened, endangered and protected (TEP) species groups such as dugongs and turtles (Limpus, 2007; Roelofs, 2002). Inshore and offshore coral reefs in the Mackay region are extensive and part of the GBR.

The community group selected for the project in Mackay was the Local Marine Advisory Committee (LMAC) (http://www.gbrmpa.gov.au/about-us/local-marine-advisory-committees). The Mackay LMAC boundaries also define the boundary for the Mackay case study. Members of the LMAC include a representative of the Great Barrier Reef Marine Park Authority (GBRMPA), a local 
councillor, members of the community (including indigenous groups) and major industry stakeholders such as North Queensland Bulk Ports Corporation (Dichmont et al., 2016).

Figure 1.

\section{$2 \quad$ Material and Methods}

\subsection{Selecting a community group in Mackay}

The LMAC meets five times a year, but for this project a more intense engagement process was required for more effective communication about the project with stakeholders and to more thoroughly include their inputs to the project. As a result the project team approached the LMAC to create a volunteer group called the LMAC Reference Group (RG) to meet with the project team more frequently to provide in-depth input and guidance to the project. Given that not all members of the LMAC volunteered for this group, the RG membership was bolstered by names provided by the Mackay LMAC who subsequently volunteered for RG membership through a GBRMPA staff member.

The engagement process pursued throughout the project was mostly with the LMAC RG, with updates and occasional input or endorsement of finalised products from the LMAC. The engagement process and sequence of events related to the elicitation and weighting of objectives for Mackay is depicted in Figure 2. Interaction with the public was undertaken as a joint venture between the LMAC and the project team. The public engagement was particularly intensive during the objective weighting stage (see details below). The RG met more than five times over 8 months for the objective elicitation and weighting and was a very engaged and active volunteer group. Actively incorporating stakeholders' inputs in our methodology-by allowing them to construct and deconstruct management objectives in formal workshop sessions-enabled participants to interpret and own the management objectives they developed. Therefore, there was a greater sense of ownership and purpose of the products developed in the research.

\section{Figure 2.}

The steps to elicit and weight management goals and objectives for the Mackay region were the following: (i) literature review of management goals and objectives from documents from government bodies, industry, non-governmental organisations (NGO) and academic literature, (ii) development of a hierarchy tree of goals and objectives, and (iii) ranking of management goals and objectives.

\subsection{Review of the literature and input from the reference group}

An extensive review of existing stated objectives in the grey and published literature, and web sites of organisations relevant to Mackay was undertaken. Existing stated objectives were categorised as social, economic and sustainability objectives. The literature search involved a web search for documents from local councils (e.g. the Mackay City Council), local coastal organisations (e.g. North 
119 Queensland Bulk Ports), local non-governmental organizations (NGO) (e.g. Reef Catchments), State

120 Government organisations and their relevant legislations (e.g. the Environment, Protection and

121 Biodiversity Act of the Department of Environment and Heritage Protection that relates to species

122 such as turtles and dugongs) and Federal Government organisations and their relevant legislations

123 using key words such as "management objectives Mackay", "Fisheries objectives Mackay", and

124 "biodiversity objectives Mackay". The academic peer-reviewed literature was also searched, which

125 included previous reviews such as fisheries management objectives for the QLD state (Pascoe et al.,

126 2013) and conservation objectives (Pressey and Bottrill, 2009; Pressey et al., 2003).

127 The sequence of key events for the project is shown in Figure 2 and summarised as follows. On the

$1285^{\text {th }}$ of December 2012, the project team presented and discussed the initial list of social, economic

129 and environmental management objectives for the Mackay inshore region sourced from the

130 literature with the RG. A draft document containing the overall objectives found in the literature was

131 circulated to participants prior to the meeting. During the meeting the original list of objectives from

132 the literature was discussed and modified with the RG. Participants also had the opportunity to send

133 their personal notes and comments to the project team after the meeting.

134 In January 2013 the project team prepared an updated list of objectives following the RG inputs. The

135 process of preparing the document included refining the initial list of objectives via aggregation,

136 addition, exclusion and re-wording of the original objectives. In the process, the project team

137 explained to RG members how the changes were considered in the updated list of objectives and the

138 RG could actually track the changes through the documents provided by the research team. The list

139 was then used to develop an objective tree.

\subsection{Objective tree}

The initial list of objectives were categorised into three hierarchies, following the definitions from West (2005): Goals (or high-level objectives, defined as the broad, high-level, final state being reached), sub-goals (mid-level, or intermediate state to be reached), and objectives (low-level or specific and shorter term state to be reached). Objectives provide a clear purpose for decisions (Pressey et al., 2003). An initial hierarchy of management objectives for Mackay was drafted and circulated to the RG for additional discussions during a half-day workshop held on the $1^{\text {st }}$ of March 2013 (sequence of events shown in Figure 2). A revised ( $2^{\text {nd }} \mathrm{draft}$ ) objective hierarchy was constructed based on inputs from participants during the March workshop and also from the Mackay LMAC on a separate meeting also held in March. The second draft of the objective tree was used in two workshops on the $15^{\text {th }}$ and $19^{\text {th }}$ of April 2013 with the Brisbane-based project team members and the RG, respectively, to start addressing the question of weights to be attributed to the different objectives, using the Analytic Hierarchy Process (Saaty, 1980, 2003).

In essence, the process of developing the goals and objective tree included the provision to the RG of an initial list of objectives from the literature, which were expanded, narrowed down and refined into a more concise set by the project team and RG (van Putten et al., 2015). This objective list was also iteratively modified and refined during the process - starting with developing the goals from the objectives sourced from the literature, and then creating the sub-goals and objectives with the final or near final objective list. Although there were some goals, sub-goals and objectives that fell into a fourth level, this level was later removed as three levels were seen as sufficient and the fourth level 
as both incomplete and too detailed. Since the weighting process used a method that considers pairwise comparison, a maximum of three branches were allowed for any one goal, and sub-goal.

\subsection{Relative importance of goals, sub-goals and objectives}

Relative weights for goals, sub-goals and objectives were obtained using two decision analysis methods based on the same mathematical principles, and three survey elicitation methods. The first was the Analytical Hierarchical Process (AHP) (Pascoe et al., 2013; Saaty, 1980) that was obtained using an Excel $^{\circledR}$ set of worksheets with Visual Basic add-ins to undertake the Saaty analysis for consistency (Pascoe et al., 2013). A maximum of ten per cent inconsistency within the respondents' answers was allowed before the comparison was deemed unusable. When this happened the respondent was asked to modify their selection. AHP is based upon the construction of a series of pairwise comparison matrices, which compare goals, sub-goals and objectives to one another. One of the advantages of the pairwise comparison method is that it makes the process of assigning weights cognitively easier because only two elements are compared at any one time instead of all objectives being compared to each other simultaneously. A detailed information sheet about the method and how to use the Excel program was provided to participants during the workshop and is presented in Appendix A. Project staff were also available for questions and further explanations during the workshops.

Three sessions were organised for respondents to complete the AHP surveys. The first was held in Brisbane on the $15^{\text {th }}$ of April 2013 with resource managers who were part of the project (see sequence of events depicted in Figure 2). A second session was held with the RG in Mackay on the $19^{\text {th }}$ of April 2013. The third AHP survey was held at a local school in Mackay from July 8-12 2013 for inputs from the general public. In all sessions, computers were set up with the AHP excel program and after an introduction about the project by the project team, respondents were asked to complete the survey. The surveys for the general public were advertised through paid newspaper advertisements, three separate radio interviews, paid Facebook advertisements, and the project website (http://www.csiro.au/gbr-mse). The project team and RG also used their own networks to recruit potential respondents.

Respondent feedback alerted the project team to the fact that respondents felt that the consistency tests required as part of the AHP method was manipulating them into providing a result by design and was not accepting their own actual score. The Excel survey was also perceived to be tedious and long-winded. As a result, the project team developed a second, mathematically identical but cognitively easier method, which uses a combination of the Point Allocation (PA) method (Bottomley and Doyle, 2001) and AHP - hereafter called the Hierarchical Point Allocation method (HPA). In the HPA method, respondents were asked to undertake 100 points allocation for goals, sub-goals and objectives respectively (as one does with the AHP), unlike the PA method where the scoring is only undertaken at the objective level. Given the number of objectives, this approach would create biases and inconsistency of responses as already articulated by research undertaken on the PA method (Bottomley and Doyle, 2001).

The project team quickly implemented the paper version in an online survey (SurveyMonkey ${ }^{\top \mathrm{M}}$ ). Community respondents who attended the public session had the option of choosing between the AHP Excel program, and/or a paper version of the HPA or the online HPA survey. After the public 
session at the local school the online HPA survey was advertised more broadly and made available to the larger Queensland community from 8 to 10 July 2013. The project team developed a second online survey that was visually more appealing and more closely resembled the paper version (the SurveyMonkey ${ }^{\mathrm{TM}}$ survey was also retained as it was already previously advertised). The link to the Survey was available on the project website ${ }^{1}$.

Data analyses were undertaken in $R$ ( $R$ Development Core Team 2007) and the default settings are used to present the results in box and whisker plots. The box shows the median (second quartile: Q2) and the first and third quartile (Q1 and Q3). The upper whisker is the $\min [\max (x) ; Q 3+1.5(Q 3-Q 1)]$ of the data vector $\mathrm{x}$ and the lower whisker is $\max \min (x) ; Q 1-1.5(Q 3-Q 1)]$. Any values outside these whiskers are shown as outliers.

\subsubsection{Defining stakeholder groups}

Additional information was obtained from surveying participants in terms of the stakeholder group they identified with i.e., a) 'residents', b) 'resource users', which includes fishers, mining, farmers, c) 'government', including Local, State and Commonwealth, also GBRMPA as an organisation representing government, and d) 'other', which includes scientists, conservation organisations, and students (Table 1). The survey also asked respondents to identify their place of residence (Table 2).

\section{Table 1.}

\section{Table 2.}

\section{$3 \quad$ Results}

\subsection{Objectives hierarchy}

The final objective hierarchy is composed of three main goals related to environmental, governance and socio-economic issues (Figure 3; Appendix B): (1) protect and restore inshore environmental assets; (2) improve governance systems (i.e. leadership, institutions, rules and decision-making processes involved in managing inshore biodiversity); and (3) improve regional economic and social well-being. Each of these (first level) goals contains additional (second level) sub-goals (e.g. 1.1 Improve ecosystem connectivity) and (third level) objectives (e.g. 1.1.1 Reduce direct impacts of infrastructure and development) (for details refer to van Putten et al., 2015). The wording, structure and final objective hierarchy (Appendix B and Figure 3) reflected the views of the RG and LMAC, as the project team only acted as facilitators. An interesting outcome of the methodology applied in Mackay is that the overarching goals selected by the RG (first level goals: environmental,

\footnotetext{
${ }^{1}$ Web address to the survey is: http://seek.hosting.exacttarget.com/EventManagement/EventPage.aspx?ispbk=clear\&SUBID=$1 \& \mathrm{JOBID}=18905231 \& \mathrm{MID}=84905$.
} 
governance, and socio-economics; Figure 3) differ from the usual triple-bottom line objectives (environmental, social and economic) often found in the literature (Pascoe et al., 2013; Taylor, 2005).

Figure 3.

\subsection{Relative importance of objectives per stakeholder group}

\subsubsection{Breakdown of survey respondents}

A total of 141 respondents undertook the survey (Figure 4), with the majority of respondents from the focal region of Mackay ( $n=92)$. The second largest number of respondents $(n=20)$ was from the region covering Caloundra to the New South Wales border, which includes Brisbane, the largest city in Queensland. Most of the respondents from Caloundra to New South Wales border are Scientists or staff from 'Government' agencies and are mostly based in Brisbane (see below and also Figure 5A). Of the total respondents, 32 undertook the AHP and 109 the HPA.

\section{Figure 4.}

The most common respondent category when analysing all survey data $(n=141)$ is 'Other', closely followed by 'Residents' and 'Government' (Figure 5A). Scientists were the major group under the category 'Other', State Government staff was the major group under 'Government', and recreational fishing was the major group under the category 'Resource Users' (Figure 5B). For the Mackay region ( $n=94)$ 'Resource Users', 'Residents', and 'Other' (Figure 6A) were the largest groups responding to the survey, mainly because there were no scientists in the Mackay area responding to the survey (Figure 6B).

Figure 5. 
Overall, the Environment goal was given the highest weighting score by respondents from all regions and the Mackay region (Figure 7 and Figure 8, respectively). Interestingly, respondents from both all regions and the Mackay region scored the governance goal as more important than the well-being goal.

Figure 7.

Figure 8.

Broken down by stakeholder groups, most groups gave the Environment objectives the highest weighting score. Only 'commercial fishers' and 'high school students' ranked the governance objective the highest (Appendix C). There were variations in the weighting of the second highest goal between stakeholder groups. 'Others' ranked the governance goal second highest, while 'Government' and 'Resource users' weighted the well-being goal second highest. There was no clear preference between governance and well-being goals for 'Residents' (Figure 9).

Figure 10.

At the objectives level (Figure 11) there were many outliers when looking at the results for all regions. This suggests that either the objectives were valued very differently by some respondents, some people had extreme views due to past experiences, or some may have had problems interpreting some of the questions (Online Ethics Center for Engineering, 2006). For respondents from the Mackay region the number of outliers was fewer and the objectives are given relatively similar weightings (Figure 12). This gives support to the hypothesis of misinterpretation of the questions for respondents from all regions as most objectives were Mackay-focused. As a result, Mackay respondents may have been able to relate better to them or had more similar values and priorities.

The three highest ranked objectives for all regions fit under the Environment goals. These are: 1.1.1 (Reduce direct impacts of infrastructure and development), 1.2.3 (Reduce influx of pollutants), and 1.1.2 (Minimise human induced changes in water flow regimes) (Figure 11). The lowest ranked environmental objective was 1.3.3 (Reduce impacts on Threatened, Endangered, Protected (TEP) species).

For the governance objectives, the top three objectives ranked by all regions were 2.1.2 (Increase compliance with environmental and resource use regulations), 2.2.2 (Increase stakeholder engagement and community ownership/stewardship), and 2.1.1 (Remove regulatory barriers to flexibility (alternative harvesting techniques, zoning, diversification in the economy)). The lowest ranked governance objectives were 2.3.1 (Increase policy integration) and 2.3.2 (Increase regulatory integration).

For the well-being goal, the three highest objectives ranked by all regions were 3.3.2 (Improve education, training, social infrastructure and networks), 3.2.3 (Ensure community equity), and 3.3.1 
(Improve workplace and family health and safety in the region). The lowest ranked objective was 3.1.2 (Improve family livelihoods in the region) (Figure 11).

When looking at Mackay only, the sequence for environmental and governance objectives was the same as for all regions (1.1.1, 1.2.3, and 1.1.2, and 2.1.2, 2.2.2 and 2.1.1, respectively). For the wellbeing objectives the first two preferred objectives were similar to all regions (3.3.2 and 3.2.3, respectively), but the third preferred objective for Mackay respondents was 3.2.2 (Conserve traditional activities and cultures) instead of 3.3.1 (Figure 12). This shows that overall both Mackay residents and non-residents rank objectives similarly.

Figure 11.

Figure 12.

\section{Discussion}

\subsection{Reflection about the collaborative method to elicit management objectives from a community group from Mackay (QLD)}

The key characteristic of the process of creating the Mackay set of goals and objectives was that there was a lot of enthusiasm and a great sense of ownership and pride by the Mackay RG. The fact that the objectives were openly discussed in a group context certainly helped the elicitation process because participants could actively see how the facilitators presented the contribution of individuals to the group. However, this is not the only factor that explains greater sense of group ownership and enthusiasm. Some aspects of the research design and approach (and research investment) and some characteristics of the region also explain ownership levels. In terms of local Mackay characteristics, the effectiveness and presence of a dedicated local person (the Mackay-based GBRMPA Liaison Manager) to link locals, stakeholders and researchers was a key element of success.

In addition, project team members spent considerable time in Mackay and were available for feedback and comments by email or phone when not in Mackay. There was also an adequate 'lead time' allowing participants time to reflect on the material presented by the project team, and also the opportunity to further develop, discuss, and negotiate project outputs in a group session involving various stakeholders for the definition of objectives and development of objective tree (refer to sections 3.1 and 3.2). Even though at times there were some heated debates and discussions about objectives, the fact that there was a great sense of respect of opinions within the RG supported an environment where people felt free to express their opinions (and accepting that their opinions might not be accepted by the group). At the time of the study there were no 'hot' political issues that divided stakeholders, and the lack of historical adversity between individuals on the LMAC and within the RG helped enormously the elicitation and ranking processes.

In Mackay, the discussions during workshops to create and rank goals and objectives were mainly focused on the environmental and governance objectives. There was some discussion of 
'precedence' in the sense that the environmental objectives need to be achieved before the socioeconomic objectives can be, or vice versa, but this did not distract the group from the overall listing of objectives. The fact that governance objectives were prominent in Mackay (Figure 8) seems to be a reflection of local stakeholder perceptions that current coastal zone management is not achieving the outcomes that they perceive as important. There were also regional issues related to compliance-as reflected in objective 2.1.2-that participants felt were strongly affecting inshore fisheries and biodiversity issues.

\subsection{Relative importance of management objectives for different stakeholders}

In the GBR, environmental issues are mostly centred on waterways, wetlands, and water quality (and to some degree water quantity or supply) (Peterson et al., 2010; Reef Water Quality Protection Plan, 2014). Therefore, it is not surprising that improving water quality was the central objective for all regions as well as for the Mackay region (Figures 10 and 11). Improving water quality has been the focus of considerable research and management efforts in the region. Water quality has also led to some division in the GBR area, as farmers were held responsible for strongly influencing water quality outcomes in the GBR (i.e., they have been identified as the major contributors to sediment, nutrients and pesticides reaching the GBR (van Putten et al., 2015)). Significant improvement in land management by farmers has occurred recently, which resulted in improvements in overall water quality in the water being discharged by rivers to the GBR (Reef Water Quality Protection Plan, 2014). The fact that respondents from all regions and Mackay rated the objectives 'reduce direct impacts of infrastructure and development' and 'reduce influx of pollutants' the highest indicates that people may be increasingly concerned about decline in water quality associated with coastal development as opposed to farming. It seems that respondents recognised the farmers' efforts to improve water quality and the need for continued support in the future to improve agricultural practices. It might also be related to the recent focus on dredging parts of the GBR in the public debate. Associated with water quality was the perceived importance to 'Improve ecosystem connectivity' (objective 1.1) and 'Improve water quality' (objective 1.2) and the management of riparian vegetation - and vegetation more generally. This was a topic of discussion with the RG as the Queensland State Government had recently (2013) changed the land-clearing legislation (amendments to the 1996 native vegetation Act) by reducing land-clearing restrictions to expand agriculture in the State (van Putten et al., 2015).

Compliance was ranked the highest Governance objective (objective 2.1.2) by all respondents and by the Mackay respondents (Figures 10 and 11, respectively). The current perception of a lack of compliance, especially related to fisheries and development activities, appears to be a major issue in the region. In a sense this governance objective is perceived to influence local well-being. For example, lack of compliance on fisheries matters negatively affects the environment, flowing on to negatively affecting local well-being (i.e. recreational fishing and income from commercial fishing). The fact that respondents ranked 'Remove regulatory barriers to flexibility' (objective 2.1.1) as the second highest governance objective reflects the strong links and dependencies between governance and well-being and the need to improve the sub-goal 'increase management effectiveness' (2.1). 'Increase stakeholder engagement and community ownership/stewardship' (objective 2.2.2) was ranked the third highest governance objective by all respondents, and suggests that people perceive this objective as essential to achieve the sub-goal 'increase management 
support' (2.2) and overall inshore biodiversity and fisheries. Interestingly, 'increase management integration' (2.3) was not perceived as relevant as the other two governance sub-goals. The RG indicated that management integration is currently not satisfactory, but would be more effective when dealing with existing issues, such as how Local, State and Federal Governments could work together over jurisdictional issues to improve compliance on matters such as roads and fisheries.

There are few surprises in the socio-economic objectives in Mackay, where respondents ranked objective 3.3.2 'Improve education, training, social infrastructure and networks' the highest. Overall the perception seems to be that building social capacity is inextricably linked to 'increase social cohesion' (3.2) and 'increase economic growth' (3.1). As in other studies, socio-economic objectives are based on growing industry profitability (tourism, agriculture, fishing, and other resource extraction such as mining and its related infrastructure), community capacity, income and employment (Dutra et al., 2011; Hodgson and Dixon, 2000; Molyneaux, 2006; Peterson et al., 2010). Aside from these general (possibly more predictable) objectives, conservation of traditional activities and culture (3.2.2) and equitable resource sharing (3.2.3) featured highly, especially among Mackay respondents; objective 3.2.2 was ranked third by Mackay respondents. In contrast, all respondents ranked objective 3.3.1 (Improve workplace and family health and safety in the region) the third highest objective. Indigenous ownership and participation in management are often stand-alone objectives in natural resource management in Australia (Smith, 2008; Smith, 2004). However, there was no specific objective about indigenous participation in management as respondents perceived that culture conservation, minimise conflicts between stakeholders and community equity (objectives 3.2.1, 3.2.2 and 3.2.3, respectively) were inclusive of indigenous participation in management procedures. This shows that Mackay residents are more concerned about increasing 'social cohesion', as opposed to 'increasing social capacity'. Precedence is again important when comparing the perspectives of locals and outsiders about priorities. From a community standpoint it is probably more relevant to have a cohesive community before increasing social capacity because ongoing issues related to social cohesion can undermine community development and social capacity (Jaffe and Quark, 2006).

Overall, the absolute scores for the environment goals were lower in Mackay than for the whole region. A possible explanation is that people outside Mackay do not perceive local socio-economic objectives as high as people from Mackay. As a result outsiders tended to give lower values to wellbeing and higher values to the environment goal.

\subsection{Using diverse perceptions about the importance of management objectives to support regional coastal zone management in the GBR}

Perception creates our experiences of the world and allows us to act (Otara, 2011). The literature suggests that perceptions from diverse stakeholder groups in a multi-objective setting such as in the GBR are often divergent and, therefore the exercise of establishing and prioritising management objectives can be challenging and often not feasible because individuals belonging to various stakeholder groups have different priorities based on their values (Maio, 2010; Pommeranz et al., 2012). However, the results from the Mackay case study illustrates that in terms of management goals and objectives for the GBR coastal zone, with a few exceptions (fishers and students; Appendix C), perceptions about the relative importance of different objectives in the coastal zone of Mackay 
converge. This shows that there is strong agreement between stakeholders on what are the important values of the coast (Otara, 2011).

The differences in priorities of commercial fishers when compared to the other stakeholder groups is most likely related to a number of critical governance issues in the Mackay region that influence fishers' perception - and therefore their ranking of goals and objectives. For example, changes to the coastal landscape through Port and Urban development are increasing competition and creating resource access issues between the indigenous, recreational, and commercial fishing sectors. Of particular concern is the growing conflict between the recreational and commercial fishers, which is at times acrimonious in Mackay and in many local areas in Queensland (Dichmont et al., 2014). The methodology we developed helps elucidate and make explicit regional goals and objectives and their importance to each of the stakeholder groups. Such information provides the basis in which these groups, along with management agencies, can negotiate actions and make critical trade-offs that are intrinsic in any NRM setting. Nevertheless, the inertia and time delays involved in problem identification, negotiations about management actions and effects of the actions in the environment can threat NRM initiatives in the GBR. This is shown in the differences of perceptions between managers and community about farmers influence in water quality as opposed to coastal development effects (section 4.2; Figures 10 and 11). This highlights the importance of establishing and ranking objectives as an iterative process between stakeholders at an early stage that must be reviewed every few years to ensure perceptions between resource users and managers are not too divergent. This does not guarantee consensus about what should be done to tackle socio-ecological problems, but will most certainly support negotiations and minimise conflicts between stakeholders by allowing them to make the necessary trade-offs to manage coastal resources.

Different stakeholders, such as industry, non-governmental, and governmental organisations, must achieve their own goals and objectives, but they must also consider external pressures from other stakeholders, including local residents. To achieve goals and objectives, stakeholders may form strategic alliances if they have common, mutually beneficial goals (Pansiri, 2005). In Mackay such alliances are currently being formed (e.g. The Healthy Waterways Alliance: http://reefcatchments.com.au/water/healthy-waterways/) and the converging stakeholder perceptions, as observed in Mackay, provide significant opportunities to encourage dialogue and negotiation between stakeholders. The approach taken in this study to elicit, develop and rank goals and objectives can certainly be used to effectively support coastal ESD in multiple-use settings such as the GBR as it encourages locals to provide input on regional objectives.

The management objectives and their priorities elicited in the research in Mackay proved to be a critical step in the development of management strategies to deal with inshore fisheries and biodiversity in the GBR region. The hierarchy tree and the objective weights were used with the RG and resource managers to develop a range of management strategies to achieve the objectives elicited in the research. Such strategies were presented as a series of storylines with local examples of issues and actions that could be used by stakeholders when negotiating the implementation of the management strategies developed during the project. In addition, separate documents containing specific management strategies were prepared and submitted to Mackay Council and Fisheries agencies, as these were the target audiences identified by the RG. The letter targeted to the Queensland Minister's Fisheries Management Review was particularly influential as it provided direction on, for example, the importance of compliance rather than creating new legislation and the 
need for greater community engagement. The project team did not receive any feedback as to the potential influence of the letter addressed to the Mackay Council CEO, whereas the fisheries Review team responded directly to the authors of the letter about the influence this work had on their report.

Even though resource managers were part of the project team and supported the project, the uptake of goals and objectives produced in this research requires a variety of organizations working in the coastal space. The influence of the project outcomes in the Queensland Fisheries Review indicates that implementing project outcomes requires also strong leadership to coordinate negotiations and communication across and within the various stakeholder groups represented in the Mackay region (Dutra et al., 2014; Otara, 2011).

\section{Conclusion}

Our research showed that the community acknowledges government investments and efforts from farmers to improving water quality in the region, but also that they are increasingly concerned with coastal development issues. The overarching goals selected by the RG ((1) protect and restore inshore environmental assets; (2) improve governance systems; and (3) improve regional well-being) demonstrate that effective governance is perceived by the RG and survey respondents to significantly influence environmental and well-being objectives. This demonstrates also that overall the community understands the links between socio-economic, environmental, and governance objectives. Such a community characteristic can strongly support integrated ESD actions. For example, respondents ranked compliance-related to fisheries and coastal development-the highest governance objective in the region, which also affects the environment and the well-being of the population. These results demonstrate the need to improve governance systems to achieve ESD outcomes in the region.

Some lessons can be learnt from the methodology applied in our research, which will be of use to future projects aimed at setting objectives for socio-ecological systems. For example, to increase essential 'ownership' of the end result (i.e. the list of objectives and the associated trees), a dedicated and preferably local project or research officer should be available at the locality for a period of time to directly interact with RG members (rather than relying on a fly in-fly out research approach). The level of ownership of the end product will no doubt increase through a workshop process at which the objectives are discussed in detail and agreed upon, and that any changes made from one workshop to the next were clearly traceable. There also needs to be enough time for participants to understand and reflect about the information presented to them in meetings and workshops and act accordingly; the whole process takes time. Furthermore it is important to have support from local management groups (such as the LMAC) to drive the process. Success largely depends on the proactive nature of the group, whereas uptake of results depends on both the ability of researchers to disseminate results and local leaders and their ability to negotiate and lobby for the regional goals and objectives elicited from the community. 
The authors would like to thank the Local Marine Advisory Committee and the broad community of Mackay for their valuable input and support throughout the project. Special thanks to the Reference Group, who guided and supported this research. The authors are grateful for the Commonwealth Scientific and Industrial Research Organisation (CSIRO) reviewers Dr Aysha Flemming and Dr Samantha Stone-Jovicich for valuable feedback on an early version of the paper and external reviewers.

This research was funded by the Department of Environment; the Commonwealth Scientific and Industrial Research Organisation (CSIRO); the Queensland State Department of Agriculture Fisheries and Forestry; the Great Barrier Reef Marine Park Authority; the Queensland State Department of Environment, Heritage and Protection; and James Cook University.

\section{References}

Australian Bureau of Statistics, 2012. Census Quickstats 2011. impact on the community outcome. Ecol. Econ. 63, 553-562. Boschetti, F., Richert, C., Walker, I., Price, J., Dutra, L., 2012. Assessing attitudes and cognitive styles of stakeholders in environmental projects involving computer modelling. Ecological Modelling 247, 98-111.

Bottomley, P.A., Doyle, J.R., 2001. A comparison of three weight elicitation methods: good, better, and best. Omega 29, 552-560.

Burt, G., 2011. Towards the integration of system modelling with scenario planning to support strategy: the case of the UK energy industry. Journal of the Operational Research Society 62, 830839.

de Geus, A.P., 1988. Planning as learning. Harvard Business Review March-April, 70-74.

Department of Transport and Main Roads, 2015. Recreational vessel registrations in Queensland as at January 2015. Maritime Safety Queensland, Brisbane.

Dichmont, C.M., Dutra, L.X.C., Owens, R., Jebreen, E., Thompson, C., Deng, R.A., van Putten, E.I., Pascual, R., Dambacher, J.M., Warne, M.S.J., Quinn, R.H., Thébaud, O., Bennett, J., Read, M., Wachenfeld, D., Davies, J., Garland, A., Dunning, M., Collier, C., Waycott, M., Playford, J., 2016. A generic method of engagement to elicit regional coastal management options. Ocean Coast. Manage. 124, 22-32.

Dichmont, C.M., Dutra, L.X.C., Thébaud, O., Putten, I.v., Deng, R., Pascual, R., Dambacher, J., Owens, R., Read, M., Thompson, C., Wachenfeld, D., Jebreen, E., Quinn, R., Dunning, M., Davies, J., Garland, A., Warne, M., Playford, J., Bennett, J., 2014. Design and implementation of Management Strategy Evaluation for the Great Barrier Reef inshore (MSE-GBR) - Progress Report. National Environmental Research Program, Cairns.

Dutra, L.X.C., Ellis, N., Perez, P., Dichmont, C.M., de la Mare, W., Boschetti, F., 2014. Drivers influencing adaptive management: a retrospective evaluation of water quality decisions in South East Queensland (Australia). Ambio 43, 1069-1081. Dutra, L.X.C., Haworth, R.J., Taboada, M.B., 2011. An integrated approach to tourism planning in a developing nation: a case study from Beloi (Timor-Leste). in: Dredge, D., Jenkins, J. (Eds.), Stories of Practice: Tourism Policy and Planning. Ashgate, Farnham, pp. 269-293. Hodgson, G., Dixon, J.A., 2000. El Nido revisited: Ecotourism, logging and fisheries, in: Cesar, H.S.J. (Ed.), Collected essays on the economics of coral reefs. CORDIO, Kalmar, Sweden, pp. 55-67. Jaffe, J., Quark, A.A., 2006. Social cohesion, neoliberalism, and the entrepreneurial community in rural Saskatchewan. American Behavioral Scientist 50, 206-225. 
Limpus, C.J., 2007. A biological review of Australian marine turtle species Flatback turtle, Natator depressus (Garman). Freshwater and Marine Sciences Unit, Environmental Sciences Division, Brisbane, p. 53. Mackenzie, A., Pidd, M., Rooksby, J., Sommerville, I., Warren, I., Westcombe, M., 2006. Wisdom, decision support and paradigms of decision making. European Journal of Operational Research 170, 172-191.

Maio, G.R., 2010. Mental Representations of Social Values. Adv Exp Soc Psychol 42, 1-43. Molyneaux, P., 2006. Economic efficiency in fisheries and aquaculture. International Journal of Transdisciplinary Research 1, 100-114. NQBP, 2014. Mackay Port. North Queensland Bulk Ports Corporation. Online Ethics Center for Engineering, 2006. Outliers in Survey Data. National Academy of Engineering Otara, A., 2011. Perception: A Guide for Managers and Leaders. Journal of Management and Strategy 2, 21-24.

Pansiri, J., 2005. The influence of managers' characteristics and perceptions in strategic alliance practice. Management Decisions 43, 1097-1113.

Pascoe, S., Dichmont, C.M., Brooks, K., Pears, R., Jebreen, E., 2013. Management objectives of Queensland fisheries: Putting the horse before the cart. Marine Policy 37, 115-122.

Peterson, A., Walker, M., Maher, M., Hoverman, S., Eberhard, R., 2010. New Regionalism and Planning for Water Quality Improvement in the Great Barrier Reef, Australia. Geographical Research 48, 297-313.

Pommeranz, A., Detweiler, C., Wiggers, P., Jonker, C., 2012. Elicitation of situated values: need for tools to help stakeholders and designers to reflect and communicate. Ethics Inf Technol 14, 285-303. Pressey, R.L., Bottrill, M.C., 2009. Approaches to landscape- and seascape-scale conservation planning: convergence, contrasts and challenges. Oryx 43, 464-475.

Pressey, R.L., Cowling, R.M., Rouget, M., 2003. Formulating conservation targets for biodiversity pattern and process in the Cape Floristic Region, South Africa. Biological Conservation 112, 99-127. Reef Water Quality Protection Plan, 2014. Report Cards. The State of Queensland, Depratment of the Premiew and Cabinet.

Rittel, H.W.J., Webber, M.M., 1973. Dilemmas in general theory of planning. Policy Sciences 4, 155169.

Roelofs, A., Roder, C., 2002. , in: (Eds.), . , pp. , 2002. Seagrass and marine resources of the Newry region and sand bay dugong Protection areas, in: Coles, R.G., Lee Long, W.J., McKenzie, L.J., Roder, C.A. (Eds.), Seagrass and Marine Resources in the Dugong Protection Areas of Upstart Bay, Newry Region, Sand Bay Llewellyn Bay, Ince Bay and the Clairview Region. Great Barrier Reef Marine Park Authority and The State of Queensland, Department of Primary Industries, Townsville, pp. 55-88. Saaty, T.L., 1980. The analytic hierarchy process: Planning, priority setting, resource allocation. McGraw-Hill International Book Co., New York and London.

Saaty, T.L., 2003. Decision-making with the AHP: Why is the principal eigenvector necessary. European Journal of Operational Research 145, 85-91. Smith, D., 2008. Cultures of governance and the governance of culture: transforming and containing Indigenous institutions in West Arnhem Land, in: Hunt, J., Smith, D., Garling, S., Sanders, W. (Eds.), Contested goverance: culture, power and institutions in indigenous Australia. Centre for Aboriginal Economic policy Research, ANU E Press, Canberra, pp. 75-111.

Smith, D.E., 2004. From Gove to Governance: Reshaping Indigenous Governance in the Northern Territory, in: Altman, J. (Ed.), CAEPR Discussion Paper Series. Centre for Aboriginal Economic Policy, Canberra, p. 43.

Taylor, A., 2005. Guidelines for Evaluating the Financial, Ecological and Social Aspects of Urban Stormwater Management Measures to Improve Waterway Health. Cooperative Research Centre for Catchment Hydrology, Melbourne, p. 168.

Thom, R.M., 2000. Adaptive management of coastal ecosystem restoration projects. Ecological Engineering 15, 365-372. 
600 Triantafillos, L., Brooks, K., Schirmer, J., Pascoe, S., Cannard, T., Dichmont, C., Thebaud, O., Jebreen, 601 E., 2014. Final Report - 2010-040-DLD - Developing and testing social objectives for fisheries

602 management. Fisheries Research and Develoment Corporation.

603 van Putten, I.E., Dichmont, C.M., Dutra, L.X.C., Thébaud, O., Deng, R.A., Jebreen, E., Owens, R.,

604 Pascual, R., Read, M., Thompson, C., 2015. Objectives for management of socio-ecological systems in 605 the Great Barrier Reef region, Australia. Regional Environmental Change, 1-15.

606 Walters, C.J., 2007. Is adaptive management helping to solve fisheries problems? Ambio 36, 304-307.

607 Ward, E., Schriefer, A.E., 1997. Dynamic scenarios: systems thinking meets scenario planning, in:

608 Fahey, L., Randall, R.M. (Eds.), Learning from the future: competitive foresight scenarios. John Wiley 609 \& Sons, New York, pp. 140-156.

610 West, D., 2005. Vickers' Concept of 'Relationship-Maintenance' as an Alternative to 'Goal-Seeking'

611 Models of Organisation: A Difference in the Notion of Control. Systemic Practice and Action Research $61218,261-274$. 


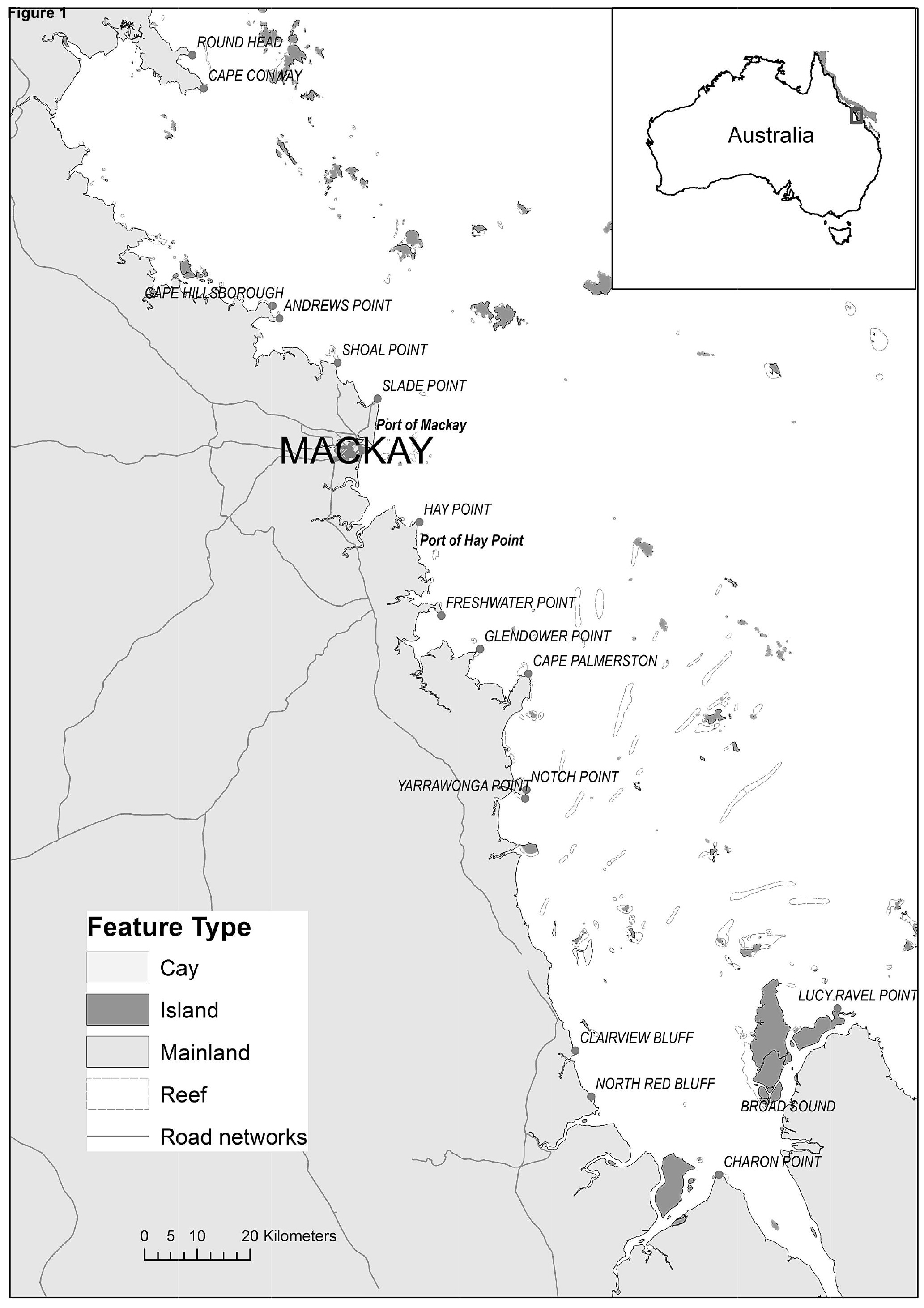




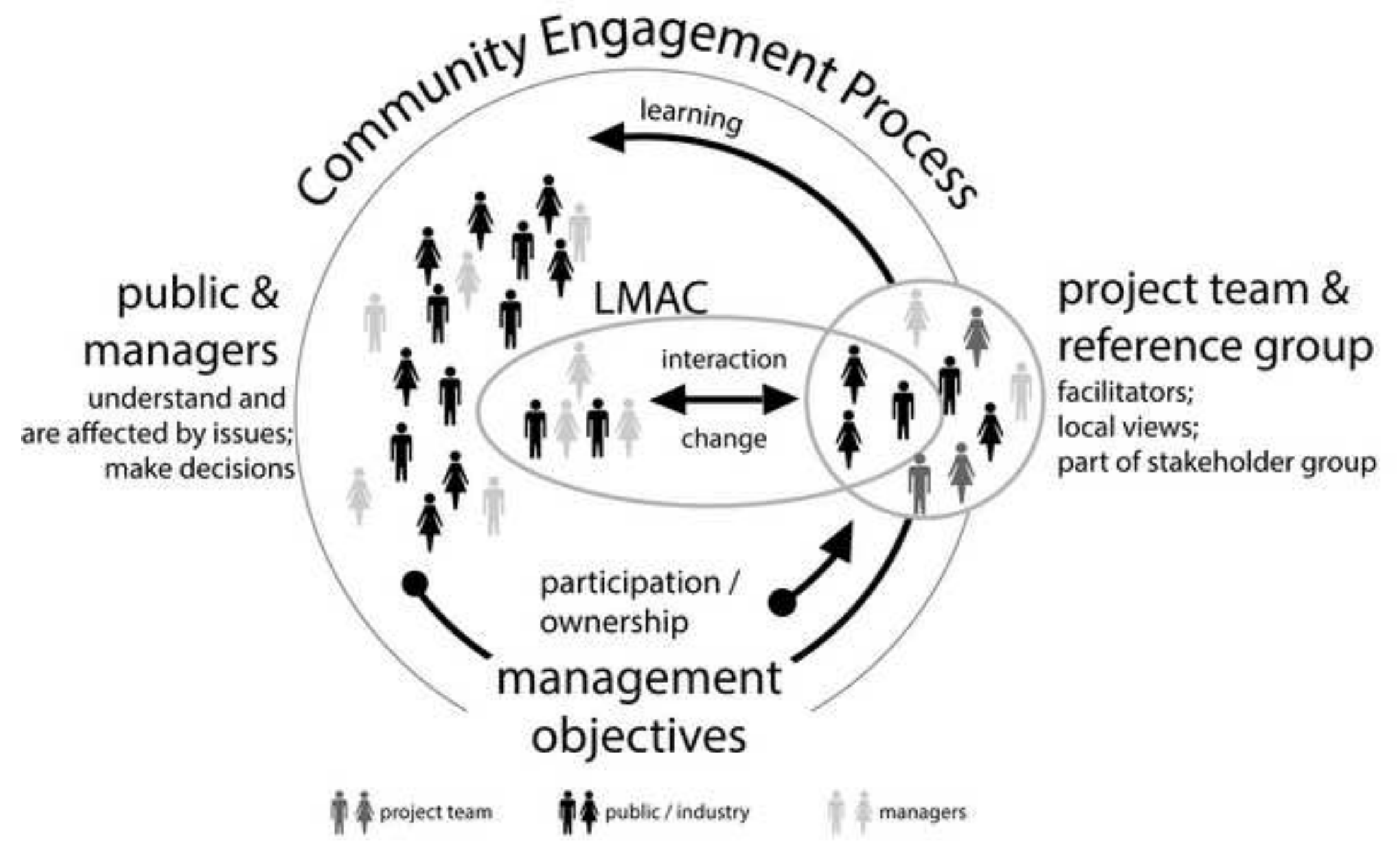

\section{Sequence of events}

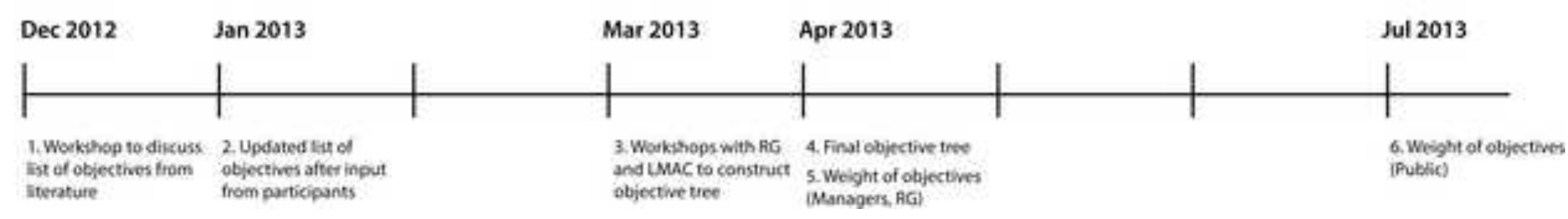




\subsection{Improve ecosystem connectivity}

\section{Protect and restore inshore environmental assets}

2. Improve governance systems (i.e. leadership, institutions, rules and decision-making processes involved in managing inshore biodiversity)

\subsection{Improve water quality}

1.3 Conserve inshore living resources effectiveness support
2.1 Increase management

2.2 increase management integration

3.1 Increase economic growth

3 Improve regional economic and social well-being
1.1.1 Reduce direct impacts of infrastructure and development

1.1.2 Minimise human induced changes in water flow regimes

1.2.1 Ensure Reef Plan water quality targets are met 1.2.2 Increase feral animal control and environmental friendly weed control strategies 1.2.3 Reduce influx of pollutants

\subsubsection{Sustainable human use of marine resources}

1.3.2 Maintain habitat function and structure 1.3.3 Reduce impacts on Threatened, Endangered, Protected (TEP) species

2.1.1 Remove regulatory barriers to flexibility (alternative harvesting techniques, zoning. diversification in the economy)

2.1 .2 Increase compliance with environmental and resource use regulations

2.2.1 Increase management acceptability

2.2.2 Increase stakeholder engagement and community ownership/stewardship

2.2.3 Sustainable financial costs

2.3.1 Increase policy integration

2,3.2 Increase regulatory integration

2.3.3 Increase implementation integration

3.1.1 Improve regional economic development and industry diversity

3.1.2 Improve family livelihoods in the region 3.1.3 Ensure that natural resource based industries are profitable and sustainable

\subsubsection{Minimise conflicts between stakeholders}

3.2 increase social cohesion

3.2.2 Conserve traditional activities and culture 3.2.3 Ensure community equity

3.3.1 Improve workplace and family health and safety in the region

3.3 Increase social capacity and networks 


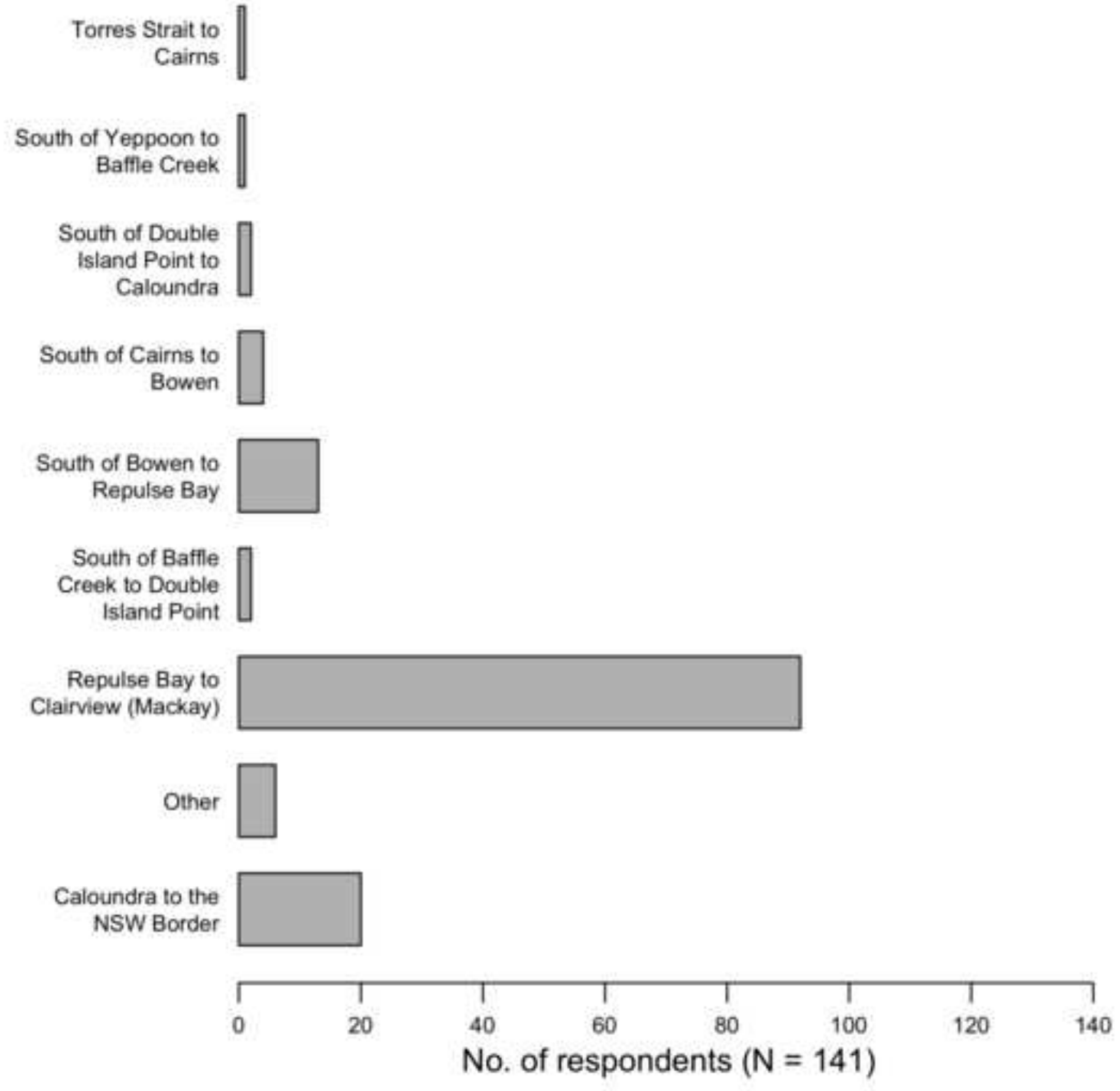

Torres Strait to
Caims

Caims

\author{
No. of respondents $(\mathrm{N}=141)$
}




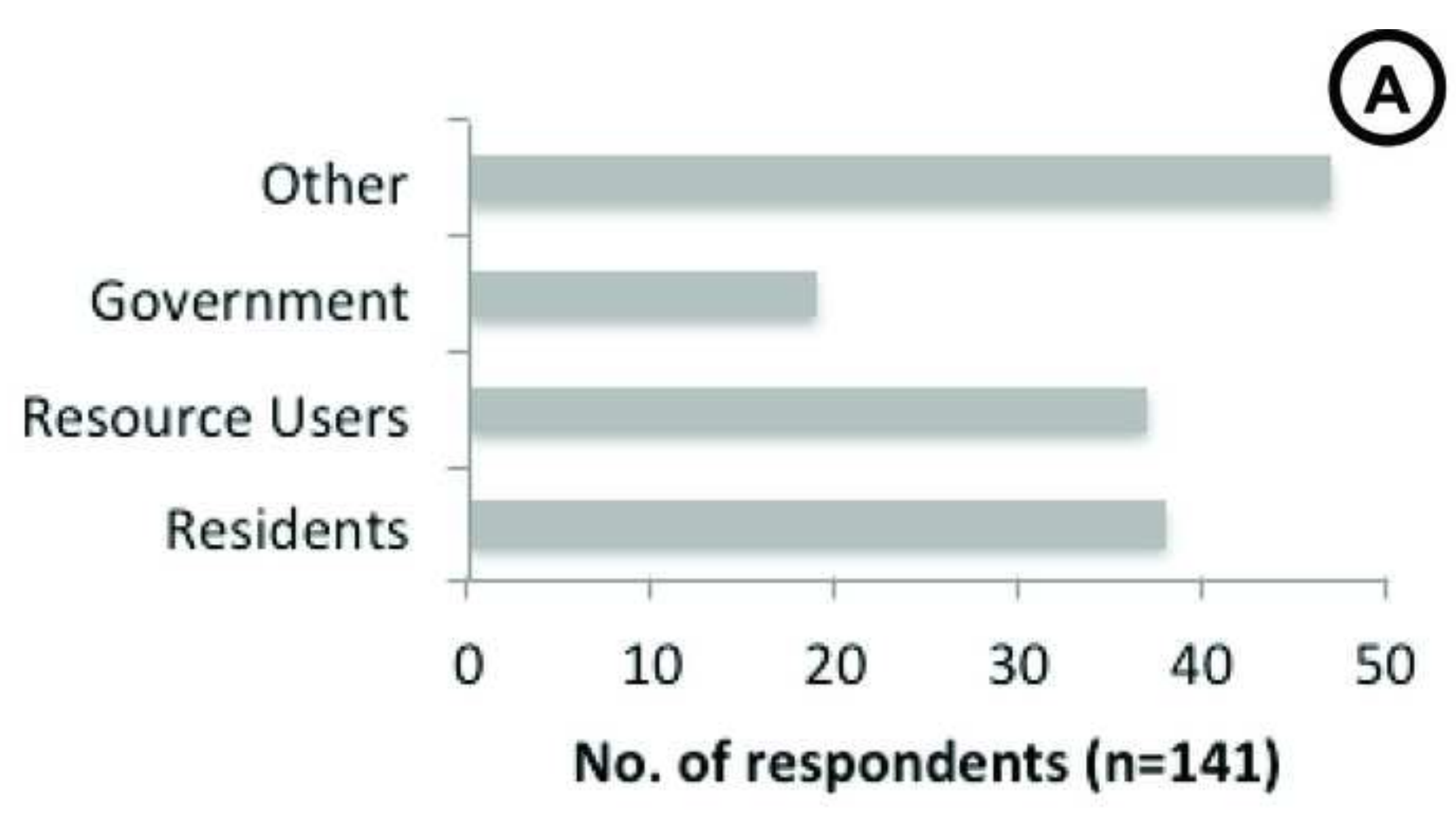

Government Residents 
Figure 5B

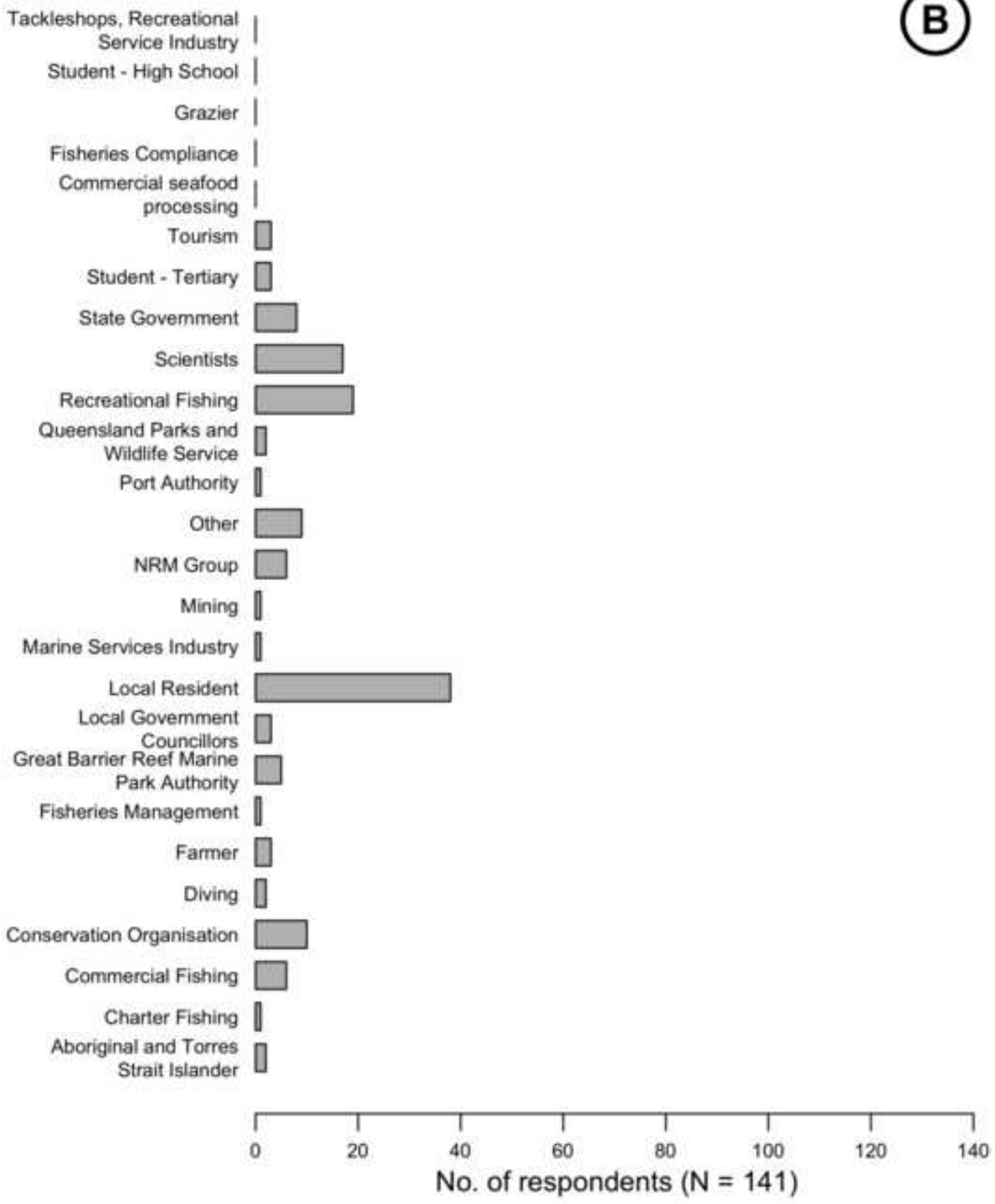




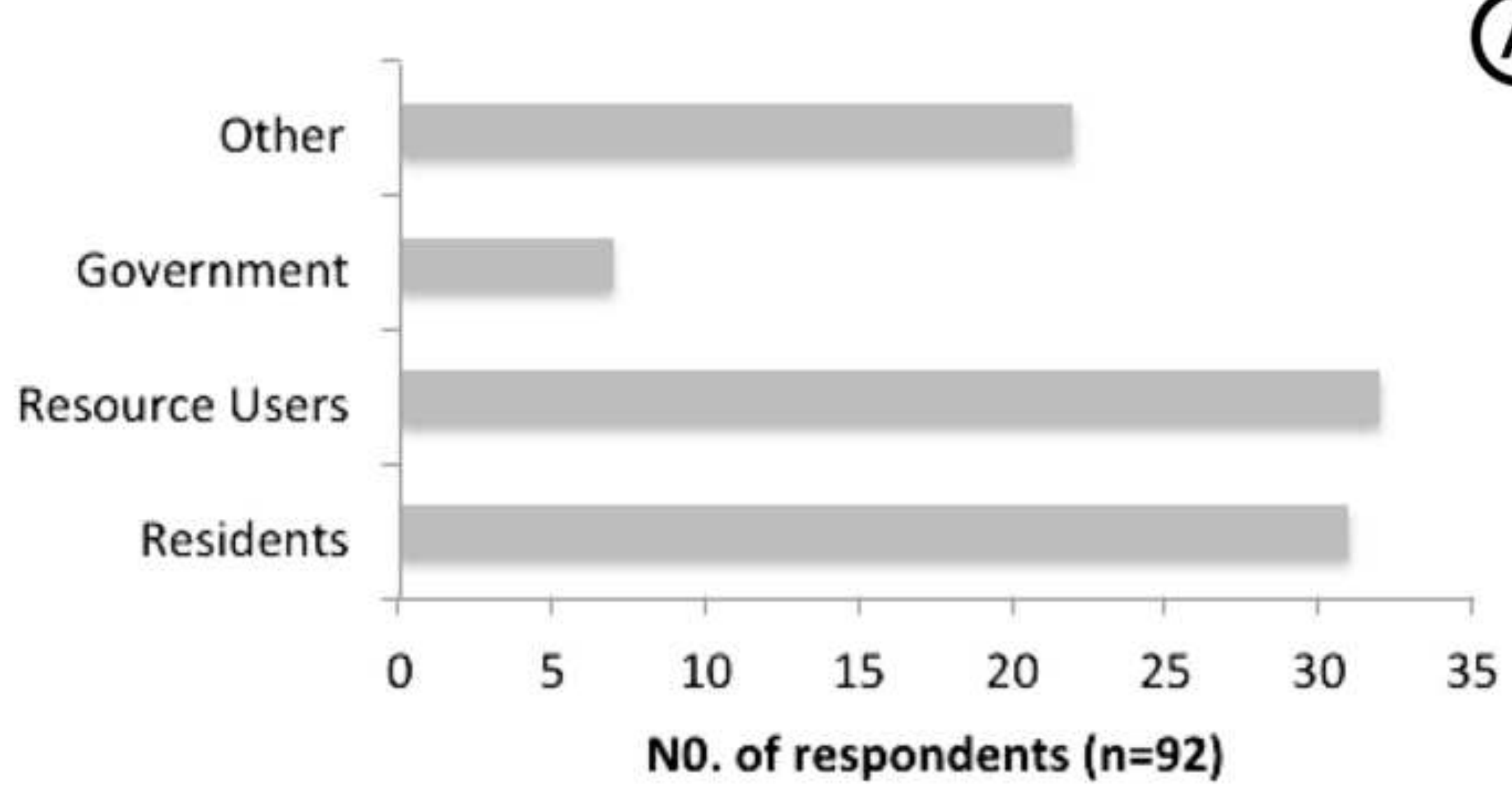

A

35

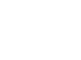


Figure 6B

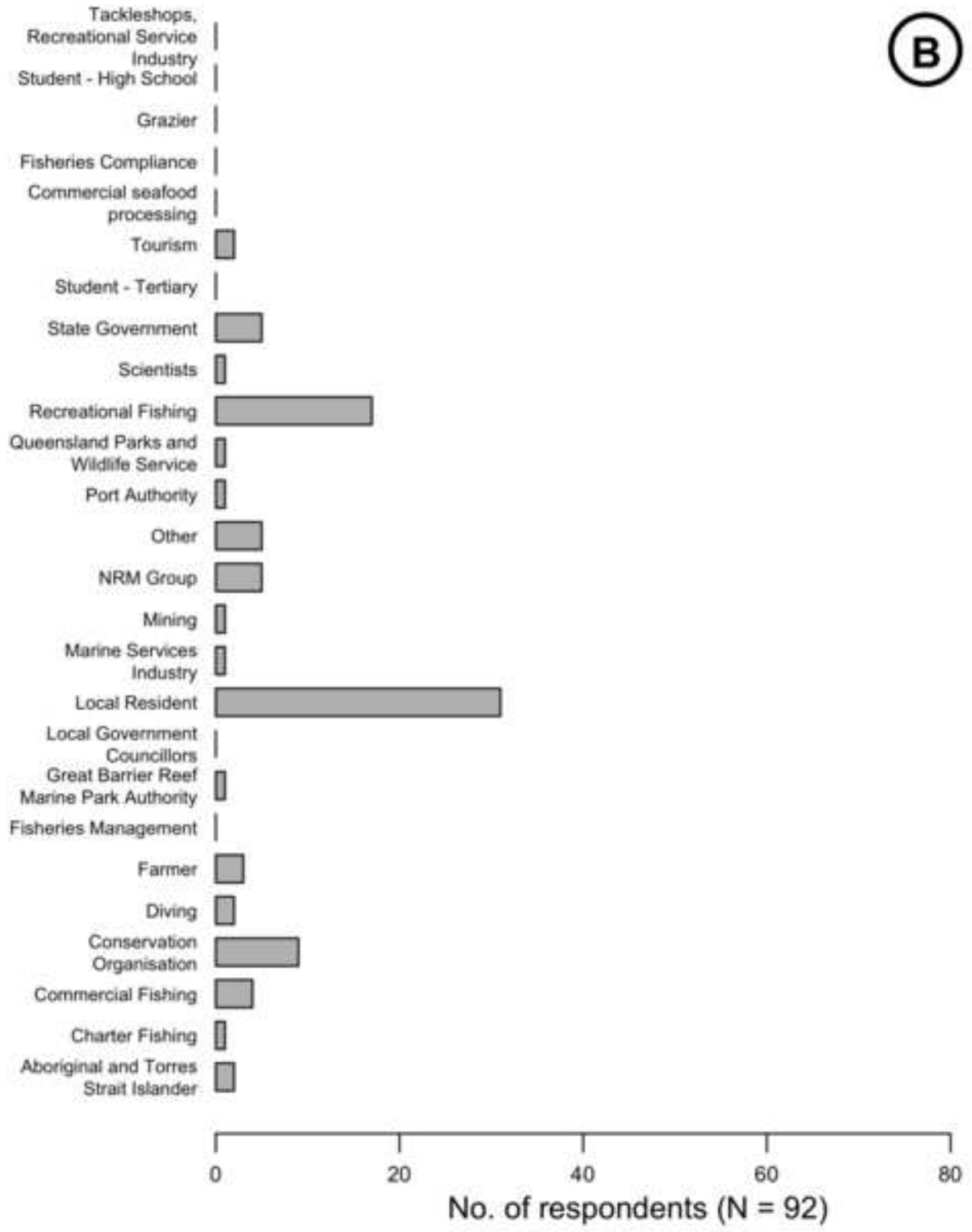

Tackleshops,

Industry
Stuident - High Schoot

Grazier

Fisheries Compliance

Student - Tertiary

Park Service

Mining

Marine Services

Industry

Local Resident

ocal Government

Councillors

Great Barrier Reef

Marine Park Authonity

Fisheries Management

Conservation

Organisation

al and Torres

Strait islander

\begin{tabular}{|c|ccc|}
\hline 0 & 1 & 1 & 80 \\
20 & No. of respondents $(\mathrm{N}=92)$ &
\end{tabular}




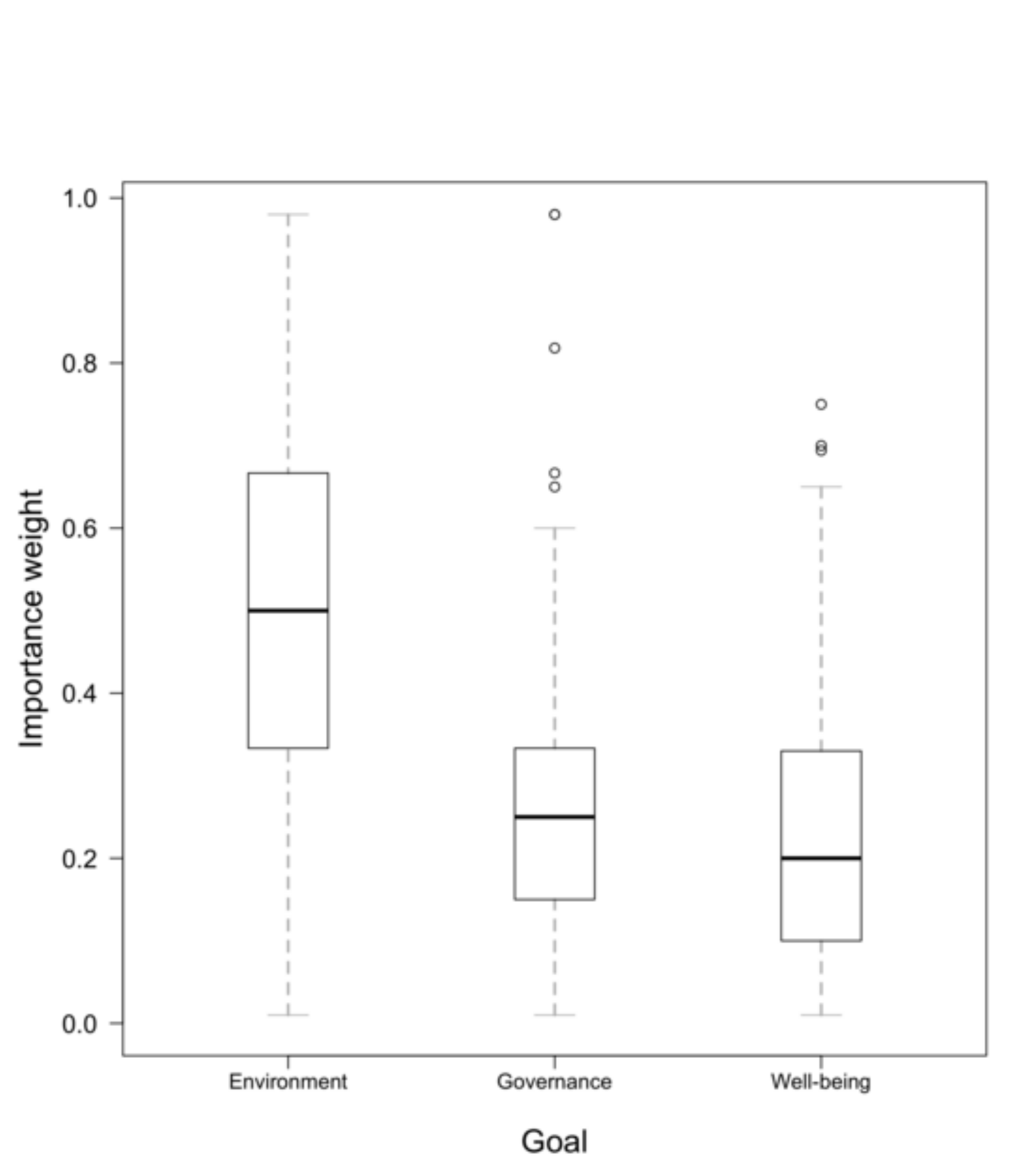

Figure 7

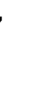

7

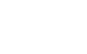




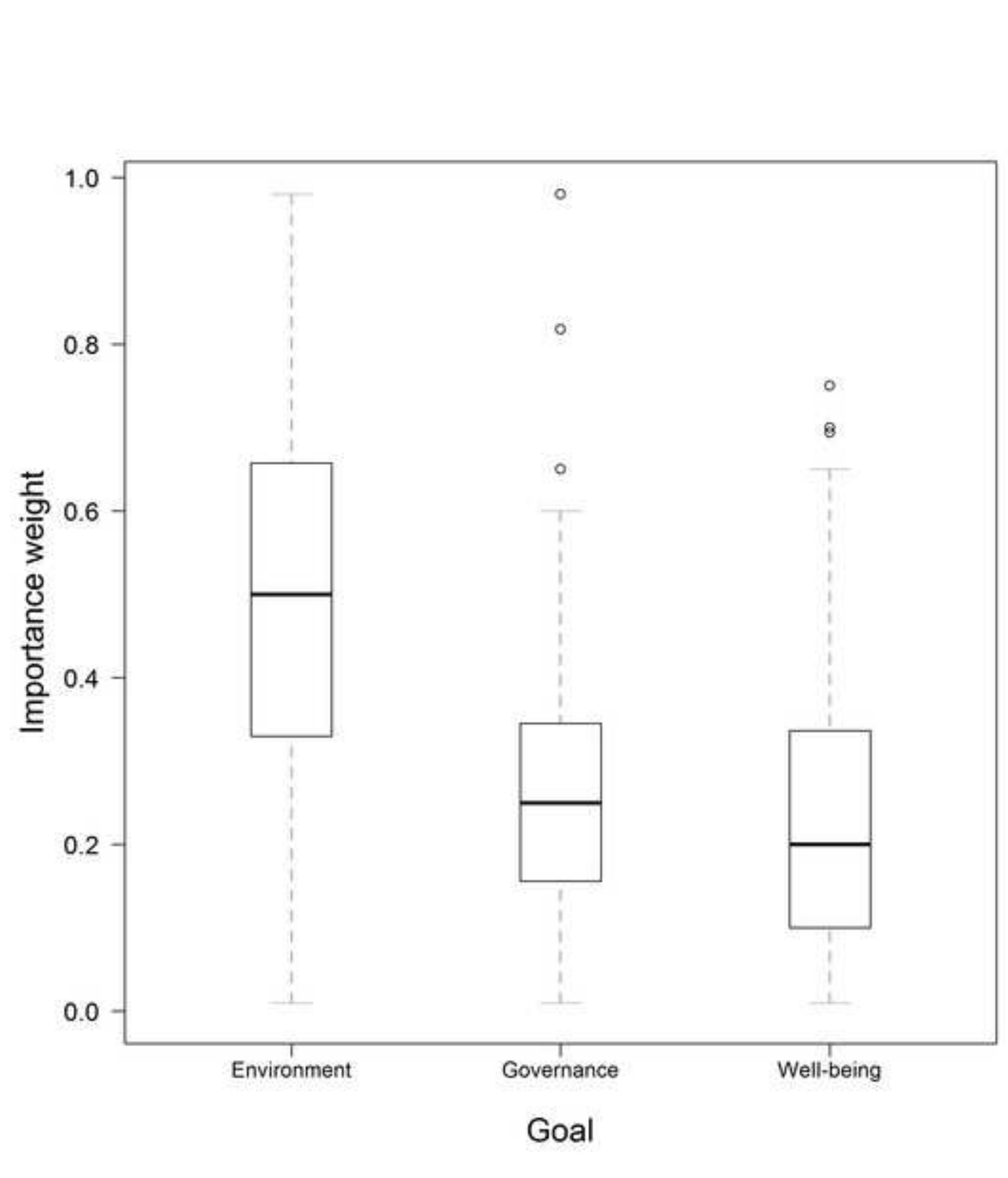

Figure 8

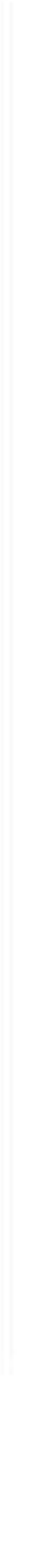

\section{Figure 8}
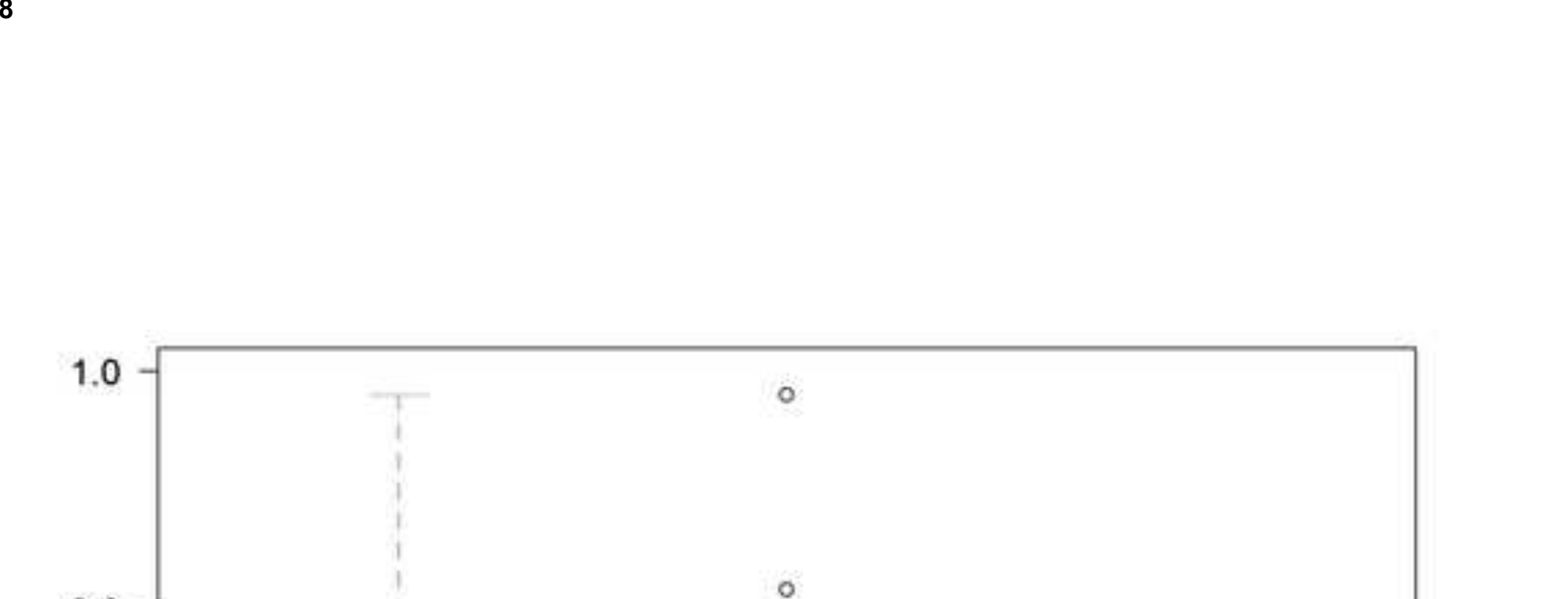
Figure 9

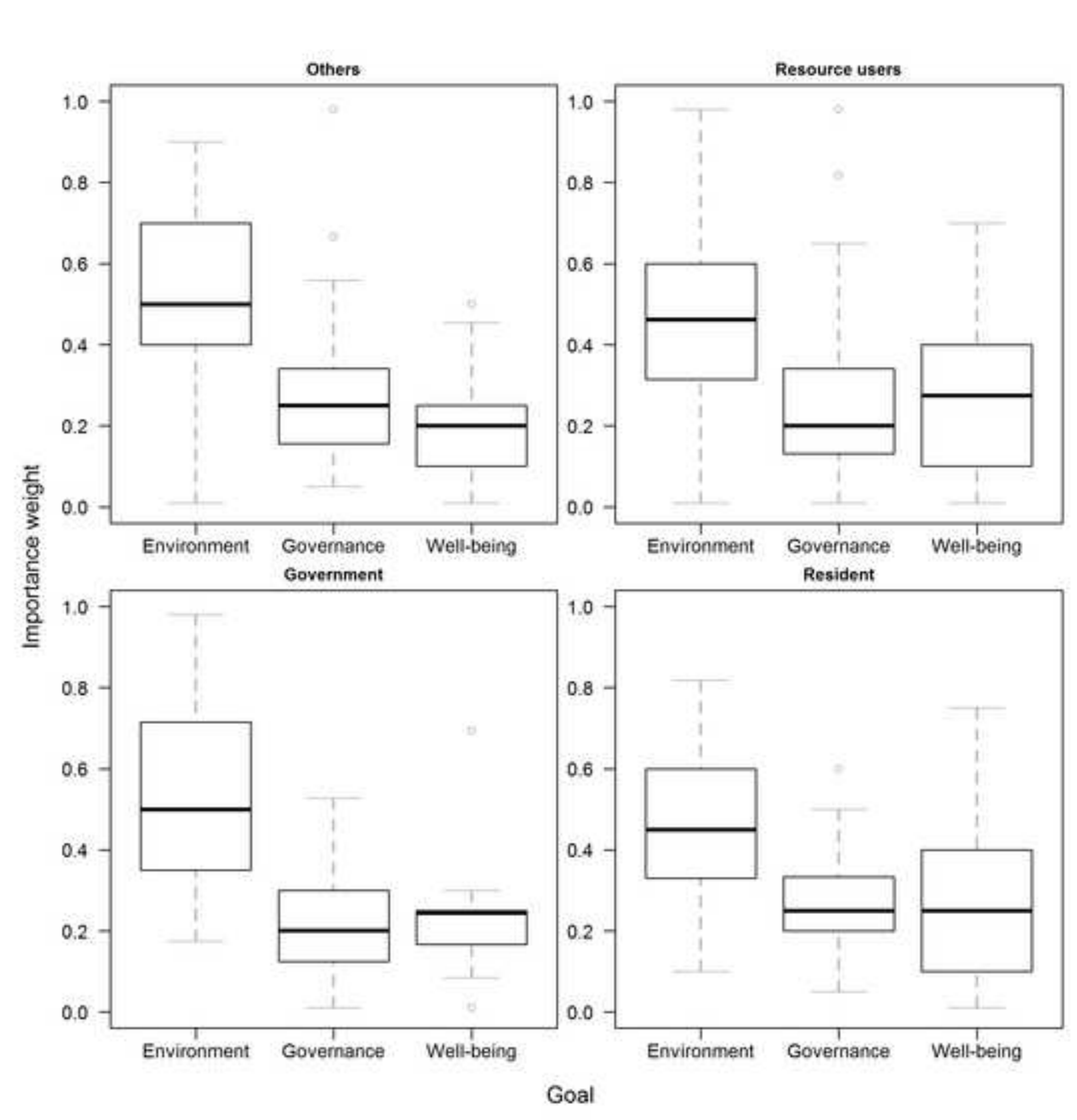
.

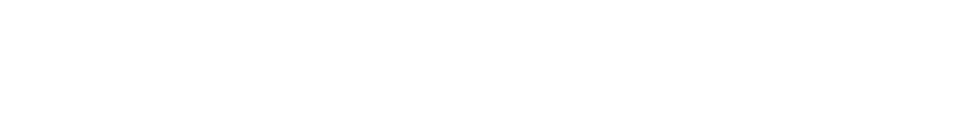


Figure 10

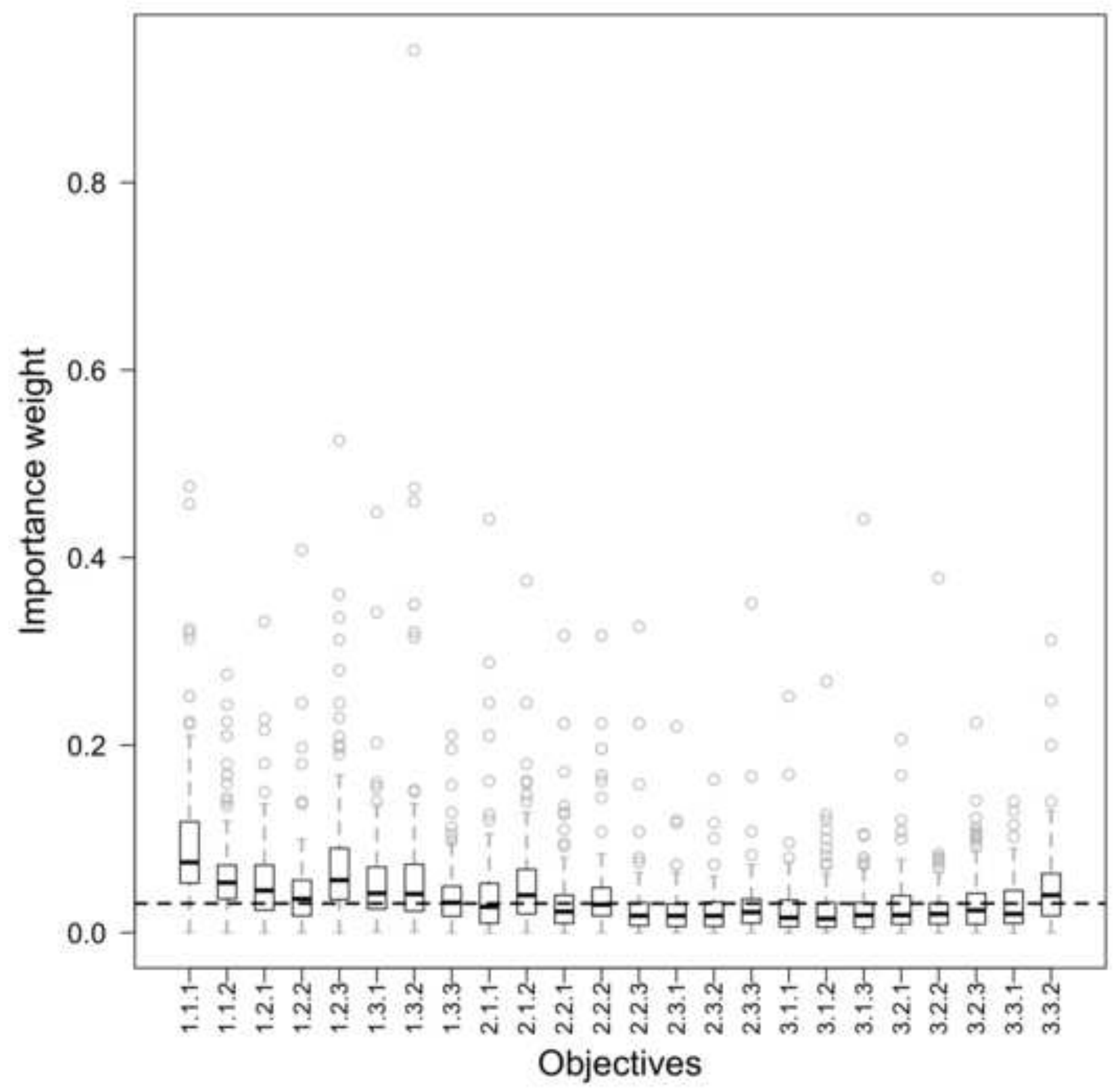




\section{Figure captions}

Figure 1. Map of the Mackay region.

Figure 2. Community engagement process used in Mackay (modified from Dutra et al., 2011) and timeline of key events.

Figure 3. Final objective hierarchy for inshore biodiversity management in the Mackay region, based on input from the Mackay Reference Group and Local Marine Advisory Committee.

Figure 4. Total number of survey respondents by region.

Figure 5. Total number of respondents for all survey respondents in groupings based on A) broader stakeholder categories, and B) stakeholders as per survey questionnaire.

Figure 6. Total number of respondents for the Mackay region in groupings based on A) Broader stakeholder categories, and B) Stakeholders as per survey questionnaire.

Figure 7. Box and whisker plot of the relative weights of the high order objectives for respondents from all regions $(n=141)$.

Figure 8. Box and whisker plot of the relative weights of goals for the Mackay region $(n=92)$.

Figure 9. Relative weights of goals per stakeholder group ( $n=141)$.

Figure 10. Box and whisker plot of the relative weights of objectives for all regions.

Figure 11. Box and whisker plot of the relative weights of the objectives for the Mackay region.

\section{$\underline{\text { Table captions }}$}

Table 1. Stakeholder types and stakeholder groups.

Table 2. Respondents' by regions. 
Table 1. Stakeholder types and stakeholder groups.

Stakeholder types

Stakeholder group

Aboriginal and Torres Strait Islander

Others

Charter Fishing

Resource users

Commercial Fishing

Resource users

Commercial seafood processing

Resource users

Conservation Organisation

Others

Diving

Resource users

Farmer

Resource users

Fisheries Compliance

Government

Fisheries Management

Government

Grazier

Resource users

Great Barrier Reef Marine Park Authority

Government

Local Government Councillors

Local Resident

Government

Resident

Marine Services Industry

Resource users

Mining

Resource users

NRM Group

Others

Other

Others

Port Authority

Queensland Parks and Wildlife Service

Resource users

Recreational Fishing

Government

Resource users

Scientists

Others

State Government

Government

Student - High School

Others

Student - Tertiary

Others

Tackleshops or Recreational Service

Industry

Resource users

Tourism

Resource users 
Table 2. Respondents by regions.

Regions

South of Baffle Creek to Double Island Point

Torres Strait to Cairns

South of Bowen to Repulse Bay

Repulse Bay to Clairview (Mackay)

South of Yeppoon to Baffle Creek

Caloundra to the NSW Border South of Cairns to Bowen

Other

South of Double Island Point to Caloundra 